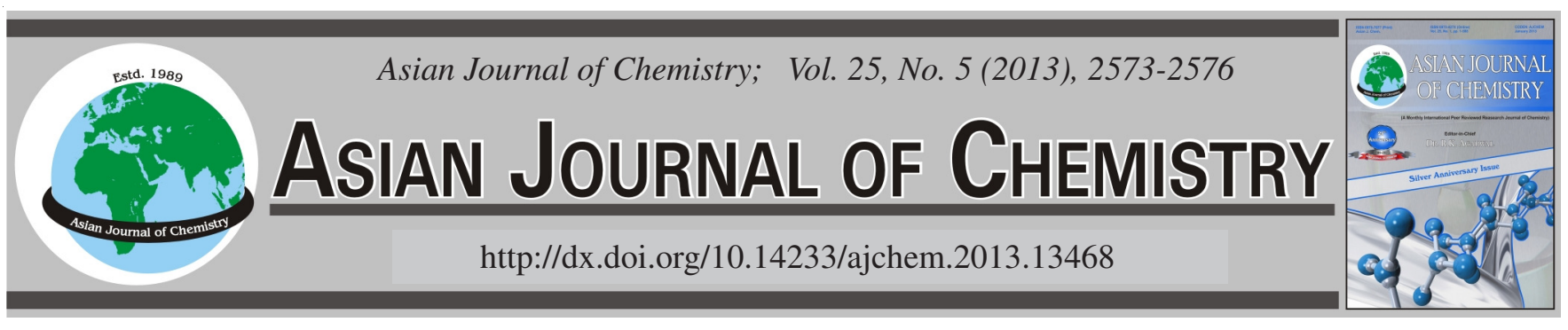

\title{
Chemical Analysis of Burdock Root Constituents
}

Zhiwu $\mathrm{Han}^{1}$, Meizhi Wang ${ }^{1}$, Longyuan Wang ${ }^{1}$, Haijun $\mathrm{Qu}^{1}, \mathrm{Ping} \mathrm{Li}^{1}$ and Chunbo Wang ${ }^{2, *}$

${ }^{1}$ The Affiliated Hospital of Medical College, Qingdao University, Qingdao 266100, P.R. China

${ }^{2}$ School of Medicine, Qingdao University, Qingdao 266071, P.R. China

*Corresponding author: E-mail: wcb2001@yeah.net

An ethanolic solution of extracted burdock root was concentrated, suspended by water and extracted by petroleum ether, chloroform, ethyl acetate and $n$-butanol. Then, the solution was purified by silica gel, Sephadex LH-20 and $\mathrm{C}_{18}$ column chromatography to obtain 17 compounds. Nine structures of compounds, identified according to physical and chemical properties using IR, UV, ESIMS, ${ }^{1} \mathrm{H}$ NMR, ${ }^{13} \mathrm{C}$ NMR and other methods, include 3 petroleum ethers ( $\beta$-sitosterol, oleanolic acid, ursolic acid), 4 chloroforms ( $\beta$-sitosterol, daucosterol, syringaresinol, ethyl- $\beta$-D-pyran fruit glycosides), 1 ethyl acetate (1,5-O-two caffeoylquinic acid) and $n$-butanol parts (succinic acid and 5-hydroxy maltol). Oleanolic acid, ursolic acid, clove lignans, ethyl- $\beta$-D-pyran fruit glycoside, succinic acid and 5-hydroxy maltol were first isolated from burdock.

Key Words: Burdock root, Petroleum ether, Chloroform, Ethyl acetate, $n$-Butanol.

\section{INTRODUCTION}

Burdock, an herb belonging to the Asteraceae family, is a traditional Chinese medicine with high food value and medicinal benefits. A number of scholars have focused on the pharmacological activity and chemical composition of the edible burdock root.

The pharmacological activities of burdock root include antibacterial $^{1,2}$, antifungal ${ }^{3}$, antimutagenic ${ }^{4}$, antitumor ${ }^{5}$, antioxidant liver ${ }^{6}$, hypoglycemic ${ }^{7}$ and promotion of plant growth as well as resistance induction ${ }^{8}$. Fresh burdock root is chemically composed of $\mathrm{ca}$. $70 \%$ water, $2.8 \%$ protein, $25 \%$ carbohydrate and $0.6 \%$ ash. Burdock root contains mostly inulin, amino acids, sulphur-acetylene class, multi-polyacetylenes, polyphenols and volatile oil, among others.

Although there are several reports on the pharmacological activity of burdock root, few studies have addressed the chemical composition, separation, purification and structural identification of the chemical composition of burdock root.

Currently, only a few details on the chemical composition and structure has been identified in burdock root, including essential oils, polyphenols, polyacetylenes, sulphur polyacetylenes and inulin. Majority of the chemical composition of this plant have not been purified. In the present study, identification of the chemical composition, purification and structure of the burdock root was performed.

\section{EXPERIMENTAL}

The burdock root medicinal pieces were from Qingdao Hao Tian Food Co. Ltd. (China).

Extraction and isolation: Burdock root herbs $(20 \mathrm{~kg})$ were obtained and extracted twice with two volumes of $95 \%$ ethanol at $50{ }^{\circ} \mathrm{C}$ for $6 \mathrm{~h}$. Ethanol was then recovered and the concentrated solution was combined and extracted. The extract was mixed with distilled water and then extracted by petroleum ether, chloroform, ethyl acetate and $n$-butanol to produce four parts with different polarities. These parts were concentrated to obtain $98 \mathrm{~g}$ petroleum ether, $100 \mathrm{~g}$ chloroform, $80 \mathrm{~g}$ ethyl acetate and $300 \mathrm{~g} n$-butanol.

Petroleum ether was eluted by petroleum ether-acetone $(100: 0 \rightarrow 0: 100$ gradient) on a silica gel column. At the 90:10 eluent, compound 1 (20 mg) was obtained, whereas compounds 2 (54 mg) and $\mathbf{3}$ (46 mg) were obtained at 85:15 eluent.

Chloroform was eluted by petroleum ether-acetone (100:0 $\rightarrow$ 0:100 gradient) on a silica gel column. At the 85:15 eluent, compounds 1 (63 mg) and $\mathbf{4}$ (44 mg) were obtained. The eluate (60:40) was collected, concentrated and further separated with Sephadex-LH 20 reversed-phase column. Compound 5 (48 $\mathrm{mg}$ ) was obtained at $40 \%$. The eluate (50:50) was collected, concentrated and further separated with $\mathrm{C}_{18}$ reversed-phase column. Compound 6 (55 mg) was obtained at $15 \%$. 
The ethyl acetate was eluted with chloroform-methanol (100:0 $\rightarrow$ 0:100 gradient) on silica gel column. The eluate (50:50) was collected, concentrated and further separated using Sephadex-LH 20 reversed-phase column. Compound 7 (74 $\mathrm{mg}$ ) was obtained at $15 \%$.

$n$-Butyl alcohol was eluted with chloroform-methanol (100:0 $\rightarrow$ 0:100 gradient) on silica gel column. Compound 8 $(52 \mathrm{mg}$ ) was obtained at $15 \%$. At 92:2 eluent ratio, compound 8 (52 mg) was obtained, whereas compound 9 (62 mg) was obtained at the 94:6 eluent ratio.

\section{RESULTS AND DISCUSSION}

The structures of nine compounds isolated from burdock root were shown in Fig. 1. Compound $\mathbf{1}$ was a white needle crystal (petroleum ether), with m.p. from $135-137^{\circ} \mathrm{C}$. Based on its purple colour at $10 \% \mathrm{H}_{2} \mathrm{SO}_{4}$ ethanol solution and Liebermann-Burchard positive test, the compound may either be triterpenoid or steroidal type. The sample and standard products were separated by thin layer chromatography (TLC), where a single spot was shown in three different systems. The $\mathrm{R}_{\mathrm{f}}$ values of the compound were the similar to those of standard product when coloured in iodine vapour and $10 \%$ $\mathrm{H}_{2} \mathrm{SO}_{4}$ ethanol solution and the melting point of the mixture did not decrease. Therefore, the compound was identified as $\beta$-sitosterol.

Compound 2 was a white needle crystal (acetic ether). In the chloroform solution, the Liebermann-Burchard reaction was positive, at the same time, based on the ${ }^{1} \mathrm{H}$ and ${ }^{13} \mathrm{C}$ NMR spectral characteristics, the compounds may be the neat trick fruit type five-ringed triterpenes. ESI-MS $\mathrm{m} / \mathrm{z}$ values were $479.2\left([\mathrm{M}+\mathrm{Na}]^{+}\right.$, excimer ion peak $), 457.2\left([\mathrm{M}+\mathrm{H}]^{+}\right.$, excimer ion peak) and $439.2\left(\left[\mathrm{M}-\mathrm{H}_{2} \mathrm{O}+\mathrm{H}\right]^{+}\right)$. The relative molecular weight was 456 and combined with ${ }^{1} \mathrm{H}$ and ${ }^{13} \mathrm{C}$ NMR spectra, the formula may be $\mathrm{C}_{30} \mathrm{H}_{48} \mathrm{O}_{3}$. In the ${ }^{1} \mathrm{H}$ NMR $\left(\mathrm{C}_{5} \mathrm{D}_{5} \mathrm{~N}, 600\right.$ $\mathrm{MHz})$ map, seven single-peak methyl proton signals were shown, as follows: $\delta$ : $0.88(3 \mathrm{H}, \mathrm{s}), 0.94(3 \mathrm{H}, \mathrm{s}), 0.99(3 \mathrm{H}, \mathrm{s})$,<smiles>CCC(C)C(C)CC[C@H](C)C1CCC2C3CC=C4C[C@@H](O)CCC4(C)C3CCC21C</smiles>

Compound 1

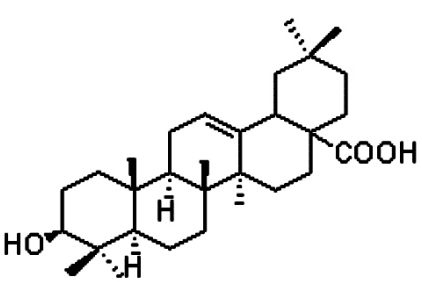

Compound 2

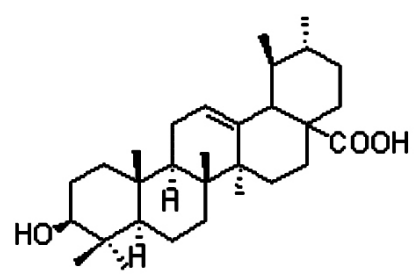

Compound 3

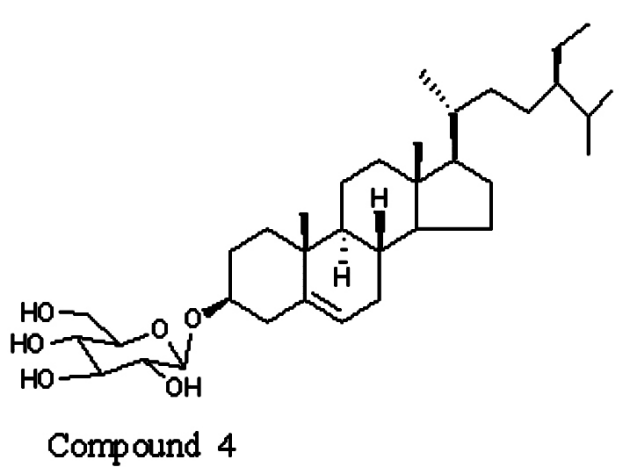<smiles>COc1cc(C2OCC3(C)[C@H](c4cc(OC)c(O)c(OC)c4)OC[C@@]23C)cc(OC)c1O</smiles>

Compound 5<smiles>CCOC1(CO)OCC(O)C(O)C1O</smiles>

Compound 6<smiles>CC(C)(CC(=O)O)CC(O)C(O)CC(=O)OC(=O)C=Cc1ccc(O)c(O)c1</smiles>

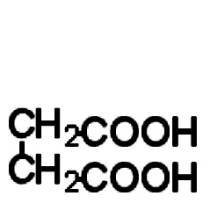

Compound 8
Compound 7<smiles>Cc1occ(O)c(=O)c1O</smiles>

Compound 9

Fig. 1. Structure elucidation of nine compounds isolated from burdock root 
$1.02(3 \mathrm{H}, \mathrm{s}), 1.02(3 \mathrm{H}, \mathrm{s}), 1.21(3 \mathrm{H}, \mathrm{s}), 1.27(3 \mathrm{H}, \mathrm{s})$. A proton signal linked with carbon oxygen $3.44(1 \mathrm{H}, \mathrm{dd}, J=9.6 \mathrm{~Hz}$, $6.0 \mathrm{~Hz})$ and one alkene hydrogen proton signal. $5.49(1 \mathrm{H}, \mathrm{s})$; ${ }^{13} \mathrm{C}$ NMR $\left(\mathrm{C}_{5} \mathrm{D}_{5} \mathrm{~N}, 150 \mathrm{MHz}\right): 38.8(\mathrm{C}-1), 28.2(\mathrm{C}-2), 77.9$ (C-3), 39.8 (C-4), 55.7 (C-5), 17.3 (C-6), 33.2 (C-7), 39.4 (C-8), 48.0 (C-9), 37.2 (C-10), 23.6 (C-11), 122.5 (C-12), 144.7 (C-13), 42.1 (C-14), 28.2 (C-15), 23.7 (C-16), 46.6 (C-17), 41.9 (C-18), 46.4 (C-19), 30.9 (C-20), 34.1 (C-21), 33.1 (C-22), 28.6 (C-23), 16.5 (C-24), 15.4 (C-25), 17.3 (C-26), 26.1 (C-27), 180.1 (C-28), 33.5 (C-29), 23.6 (H-30). The ${ }^{13} \mathrm{C}$ NMR data were the similar to those of a previous report ${ }^{9}$. Both $R_{f}$ values were exactly the same when the compound and oleanolic acid control were separated with TLC. Thus, the compound was identified as oleanolic acid.

Compound 3 was a white needle crystal (acetic ether). In the chloroform solution, the Liebermann-Burchard reaction was positive. ESI-MS m/z values were $479.2\left([\mathrm{M}+\mathrm{Na}]^{+}\right.$, excimer ion peak), $457.2\left([\mathrm{M}+\mathrm{H}]^{+}\right.$, excimer ion peak) and $439.2\left(\left[\mathrm{M}-\mathrm{H}_{2} \mathrm{O}+\mathrm{H}\right]^{+}\right)$. At the same time, based on the ${ }^{1} \mathrm{H}$ and ${ }^{13} \mathrm{C}$ NMR spectral characteristics, the compounds may be ursane five-ringed triterpenes. The relative molecular weight was 456 and the formula was $\mathrm{C}_{30} \mathrm{H}_{48} \mathrm{O}_{3}$. In the ${ }^{1} \mathrm{H} \mathrm{NMR}\left(\mathrm{C}_{5} \mathrm{D}_{5} \mathrm{~N}\right.$, $600 \mathrm{MHz}$ ) map, seven methyl proton signals could be seen, consisting of five single and two twin peaks, as follows: $\delta$ : $0.88(3 \mathrm{H}, \mathrm{s}), 0.95(3 \mathrm{H}, \mathrm{d}, J=6.6 \mathrm{~Hz}), 0.99(3 \mathrm{H}, \mathrm{d}, J=4.8 \mathrm{~Hz})$, $1.00(3 \mathrm{H}, \mathrm{s}), 1.02(3 \mathrm{H}, \mathrm{s}), 1.22(3 \mathrm{H}, \mathrm{s}), 1.24(3 \mathrm{H}, \mathrm{s})$. One proton signal linked with carbon oxygen $3.46(1 \mathrm{H}, \mathrm{dd}, J=$ $10.3 \mathrm{~Hz}, 6.6 \mathrm{~Hz}$ ) and one alkene hydrogen proton signal 5.49 $(1 \mathrm{H}, \mathrm{s}) .{ }^{13} \mathrm{C}$ NMR $\left(\mathrm{C}_{5} \mathrm{D}_{5} \mathrm{~N}, 150 \mathrm{MHz}\right): 39.0(\mathrm{C}-1), 28.0(\mathrm{C}-2)$, 78.0 (C-3), 39.3 (C-4), 55.7 (C-5), 18.7 (C-6), 33.5 (C-7), 39.6 (C-8), 48.0 (C-90), 37.3 (C-10), 17.4 (C-11), 125.5 (C12), 139.2 (C-13), 42.4 (C-14), 28.7 (C-15), 24.8 (C-16), 48.0 (C-17), 53.4 (C-18), 39.8 (C-19), 39.4 (C-20), 31.0 (C-21), 37.3 (C-22), 28.7 (C-23), 15.6 (C-24), 16.5 (C-25), 17.4 (C26), 23.5 (C-27), 179.8 (C-28), 23.8 (C-29), 21.3 (H-30). The ${ }^{13} \mathrm{C}$ NMR data were similar to those of a previous report ${ }^{10}$. The $R_{f}$ values were exactly the same when the compound and the ursolic acid control were separated with TLC. Therefore, the compound was identified as ursolic acid.

Compound 4 was a white needle crystal $(80 \% \mathrm{EtOH})$, m.p. $>300^{\circ} \mathrm{C}$. The Liebermann-Burchard reaction was positive and the colour was purple when dyed with $10 \% \mathrm{H}_{2} \mathrm{SO}_{4}$ ethanol solution. IR $\left(\mathrm{KBr}, \mathrm{v}_{\max }, \mathrm{cm}^{-1}\right)$ : produced 3432, 2936, 1636, 1540, 1461, 1383 and 1025 absorption peaks, which were similar with the IR values. The $\mathrm{R}_{\mathrm{f}}$ values of the compound were the same as the daucosterol standard when they were separated with TLC and the melting point of the mixture did not decrease. Therefore, the compound was identified as daucosterol.

Compound 5 was colourless crystalline (methanol), where m.p. is from $177-178{ }^{\circ} \mathrm{C},[\alpha]_{\mathrm{D}}{ }^{20}=-3.36^{\circ}(\mathrm{c}=0.24$, chloroform). ESI-MS showed $\mathrm{m} / \mathrm{z}$ values of $441.1\left([\mathrm{M}+\mathrm{Na}]^{+}\right), 417.0$ $\left([\mathrm{M}-\mathrm{H}]^{+}\right)$and $859.4\left([2 \mathrm{M}+\mathrm{Na}]^{+}\right)$excimer ion peak. Combined with ${ }^{1} \mathrm{H}$ and ${ }^{13} \mathrm{C}$ NMR data, the relative molecular mass of the compound was determined as 418, molecular formula was $\mathrm{C}_{22} \mathrm{H}_{26} \mathrm{O}_{8}$ and its unsaturation was 10 . In the ${ }^{1} \mathrm{H} \mathrm{NMR}\left(\mathrm{CDCl}_{3}\right.$, $600 \mathrm{MHz})$ map, $\delta: 3.92\left(12 \mathrm{H}, \mathrm{s}, 4 \times \mathrm{OCH}_{3}\right)$ was the hydrogen signal on four 7-hydroxy, $\delta: 6.61(4 \mathrm{H}, \mathrm{s})$ was the hydrogen signal on benzene rings and $\delta: 3.12\left(2 \mathrm{H}, \mathrm{m}, \mathrm{H}-8 \mathrm{H}-8^{\prime}\right), \delta: 3.92$
(2H, m, H-9e, H-9'e), $\delta: 4.31$ (2H, m, H-9a, H-9'a), $\delta: 4.75$ ( $2 \mathrm{H}, \mathrm{d}, J=3.0 \mathrm{~Hz}, \mathrm{H}-7, \mathrm{H}-7$ ') $, \delta: 5.58$ (2H, br s, 4-OH, 4'-OH) proton signals. Combined with $\delta 86.1$ (C-7, C-7'), $\delta 71.8$ (C-9, C-9') and $\delta 54.3$ (C28, C28'), three carbon signals in the ${ }^{13} \mathrm{C}$ NMR spectrum suggest that the compound may be epoxy lignin. The fragrant area of ${ }^{13} \mathrm{C}$ NMR spectrum appeared at $\delta$ 102.6 (C-2, C-2', C-6, C-6'), 132.1 (C-1, C-1'), 134.2 (C-4, C$\left.4^{\prime}\right)$ and 147.1 (C-3, C-3', C-5, C-5') carbon signals, suggesting the symmetry of the molecular structure. The above data were similar to those of a previous report ${ }^{11}$, identifying the compound as syringaresinol.

Compound 6 was colourless, crystalline and granular (aquiferous ethanol). Molisch reaction and fennel aldehyde acid reaction were positive. ESI-MS m/z were 439.9 ([M + M $+\mathrm{Na}]^{+}$, excimer ion peak), $230.8\left([\mathrm{M}+\mathrm{Na}]^{+}\right.$, excimer ion peak), $209.0\left([\mathrm{M}+\mathrm{H}]^{+}\right.$excimer ion peak), $179.9\left[\mathrm{M}-\mathrm{C}_{2} \mathrm{H}_{5}\right]^{+}$. In the ${ }^{1} \mathrm{H}$ NMR $\left(\mathrm{D}_{2} \mathrm{O}, 600 \mathrm{MHz}\right)$ map, the mutual coupling of proton signal in two groups could be seen, $\delta 1.05(3 \mathrm{H}, \mathrm{t}, J=$ $\left.7.2 \mathrm{~Hz}, \mathrm{H}-2^{\prime}\right)$ and $\delta 3.66\left(2 \mathrm{H}, \mathrm{q}, J=7.2 \mathrm{~Hz}, \mathrm{H}-1^{\prime}\right)$. The compound contained $\mathrm{CH}_{3}-\mathrm{CH}_{2}-\mathrm{O}$-segment, where 14.5 (C-2 ') and $56.6\left(\mathrm{C}-1^{\prime}\right)$ could be seen in the ${ }^{13} \mathrm{C}$ NMR $\left(\mathrm{D}_{2} \mathrm{O}, 150 \mathrm{MHz}\right)$ map data and further confirmed that the compound included the $\mathrm{CH}_{3}-\mathrm{CH}_{2}-\mathrm{O}$ segment. Five even oxygen carbon signals (69.5 [C-3], 69.1 [C-4], 68.1 [C-5], 63.7 [C-6] and 61.2 [C1]) and a ketal carbon signal 100.5 (C-2) were also observed in the carbon map. These data were similar to those of a previous report ${ }^{12}$, identifying the compound as ethyl- $\beta$-D-pyranoid fructoside.

Compound 7 was yellow powder with positive $\mathrm{FeCl}_{3}$ reaction. The ${ }^{1} \mathrm{H}$ NMR data were $\left(600 \mathrm{MHz}, \mathrm{DMSO}-d_{6}\right) \delta$ : 7.48 (1H, d, $J=15.6 \mathrm{~Hz}, \mathrm{H}-7 "), 7.37$ (1H, d, $J=15.6 \mathrm{~Hz}, \mathrm{H}-$ 7'), 7.10 (1H, s, H-2"), 7.05 (1H, s, H-2'), 6.96 (1H, d, J = 7.8 Hz, H-6"), 6.93 (1H, d, J=7.8 Hz, H-6'), 6.75 (1H, d, $J=7.8$ Hz, H-5"), 6.73 (1H, d, $J=7.8$ Hz, H-5'), 6.25 (1H, d, $J=15.6$ Hz, H-8"), 6.18 (1H, d, J = 15.6 Hz, H-8'), 5.26 (1H, m), 4.04 $(1 \mathrm{H}, \mathrm{m})$ and $3.53(1 \mathrm{H}, \mathrm{m})$. The ${ }^{13} \mathrm{C} \mathrm{NMR}$ data were $(125 \mathrm{MHz}$, DMSO-d6) $\delta: 81.8$ (C-1), 34.7 (C-2), 68.6 (C-3), 72.1 (C-4), 70.3 (C-5), 37.4 (C-6), 174.0 (C-7), 125.6 (C-1), 125.2 (C-1'), 115.8 (C-2'), 115.9 (C-2"), 143.6 (C-3'), 144.6 (C-3"), 148.1 (C-4'), 148.8 (C-4"), 114.9 (C-5', C-5"), 120.1 (C-6'), 121.2 (C-6"), 145.8 (C-7', C-7"), 114.2 (C-8"), 165.0 (C-9') and 166.2 (C-9"). The physical and chemical properties, as well as spectral data, were similar to those of a previous report ${ }^{13}$, identifying the compound as 1-O-, 5-O-dicaffeoylquinic acid.

Compound 8 consisted of colourless particles (methanol) with negative ESI-MS m/z values, namely, 116.8 ([M-H] ${ }^{-}$ excimer ion peak) and $101.0\left[\mathrm{M}+\mathrm{H}-\mathrm{H}_{2} \mathrm{O}\right]^{+}$. The relative molecular mass was 118 . In the ${ }^{1} \mathrm{H}$ NMR (DMSO- $d_{6}, 600$ $\mathrm{MHz}$ ) map, two groups of single-peak proton signals could be seen, with a ratio of $1: 2, \delta: 2.42(4 \mathrm{H}, \mathrm{s})$ and $12.15(2 \mathrm{H}, \mathrm{s})$. A carboxyl and aliphatic carbon was shown in the ${ }^{13} \mathrm{C}$ NMR (DMSO- $d_{6}, 150 \mathrm{MHz}$ ) mapping data and both $\mathrm{R}_{\mathrm{f}}$ values were exactly the same when the compound and succinic acid standard product were separated with TLC. Therefore, the compound was identified as succinic acid.

Compound 9 was a light yellow crystal with m.p. from 218-222 ${ }^{\circ} \mathrm{C}$ and showed deep purple in TLC with $\mathrm{FeCl}_{3}$ solution at $105^{\circ} \mathrm{C}$. ESI-MS m/z values were $142.9[\mathrm{M}+\mathrm{H}]^{+}$ and $164.8[\mathrm{M}+\mathrm{Na}]^{+}$. The relative molecular mass was 142 . 
${ }^{1} \mathrm{H}$ NMR data were $\left(600 \mathrm{MHz}, \mathrm{DMSO}-d_{6}\right) \delta: 8.96(1 \mathrm{H}$, br s, $-\mathrm{OH}), 8.79$ (1H, br s, -OH), 7.95 (1H, s, H-6), 2.23 (3H, s, $\left.\mathrm{CH}_{3}\right)$ and ${ }^{13} \mathrm{C}$ NMR data were $\left(125 \mathrm{MHz}, \mathrm{DMSO}-d_{6}\right) \delta: 168.9$ (C-4), 149.6 (C-2), 144.7 (C-5), 141.8 (C-3), 139.4 (C-6) and 14.8 (C-7). The physical and chemical properties, as well as spectral data, were similar to those of a previous report ${ }^{14}$, identifying the compound as 5-oxymaltol.

\section{ACKNOWLEDGEMENTS}

This study was supported by the National Natural Science Foundation of China (No: 81173593) and the Development of Science and Technology Plan Projects of Shandong Province, China (2010GNC10924).

\section{REFERENCES}

1. F.B. Holetz, G.L. Pessini, N.R. Sanches, D.A. Cortez, C.V. Nakamura and B.P. Filho, Mem. Inst. Oswaldo Cruz., 97, 1027 (2002).

2. M. Takasugi, S. Kawashima and N. Katsui, Phytochemistry, 26, 2957 (1987).
3. L.C. Chiang, W. Chiang, M.Y. Chang, L.T. Ng and C.C. Lin, Antiviral Res., 55, 53 (2002).

4. K. Miyamoto, M. Nomura, M. Sasakura, E. Matsui, R. Koshiura, T. Murayama, T. Furukawa, T. Hatano, T. Yoshida and T. Okuda, Cancer Res., 84, 99 (1993).

5. C. Tamayo, M.A. Richardson, S. Diamond and I. Skoda, Phytother. Res., 14, 1 (2000).

6. S.C. Lin, C.H. Lin, C.C. Lin, Y.H. Lin, C.F. Chen, I.C. Chen and L.Y. Wang, J. Biomed. Sci., 9, 401 (2002).

7. M. Mitsuo, Y. Nobuo and T. Katsuya, J. Oleo. Sci., 54, 589 (2005).

8. F.D. Wang, G.H. Feng and K.S. Chen, Postharvest Biol. Technol., 52, 110 (2009).

9. H. Kojinna and H. Ogura, Phytochemistry, 25, 729 (1986).

10. D.T. Coxon and J.W. Wells, Phytochemistry, 19, 1247 (1980).

11. M.M. Badawi, S.S. Handa, A.D. Kinghorn, G.A. Cordell and N.R. Farnsworth, J. Pharm. Sci., 72, 1285 (1983).

12. H.X. Kuang, R. Kasai, K. Ohtani, Z.S. Liu, C.S. Yuan and O. Tanaka, Chem. Pharm. Bull., 37, 2232 (1989).

13. Z.J. Jia, Y. Zhao and R.X. Tan, J. Nat. Prod., 56, 494 (1993).

14. Y. Shinoda, M. Murata, S. Homma and H. Komura, Biosci. Biotechnol. Biochem., 68, 529 (2004). 